\title{
Overlap between age-at-onset and disease- progression determinants in Huntington disease
}

N. Ahmad Aziz, MD, PhD, Jorien M.M. van der Burg, MD, PhD, Sarah J. Tabrizi, MD, PhD, and G. Bernhard Landwehrmeyer, MD, PhD

Neurology ${ }^{\circledR}$ 2018;90:e2099-e2106. doi:10.1212/WNL.0000000000005690
Correspondence

Dr. Aziz

Ahmad.Aziz@dzne.de or

N.A.Aziz@lumc.nl

\section{RELATED ARTICLE}

\section{Editorial}

Ameliorating the age at onset and disease progression in Huntington disease

Page 1087

\section{Methods}

Using observational data from Enroll-HD, the largest cohort of patients with HD worldwide, in this study we present, validate, and apply an intuitive method based on linear mixed-effect models to quantify the variability in the rate of disease progression in HD.

\section{Results}

A total of 3,411 patients with HD met inclusion criteria. We found that (1) about two-thirds of the rate of functional, motor, and cognitive progression in HD is determined by the same factors that also determine age at onset, with CAG repeat-dependent mechanisms having by far the largest effect; (2) although expanded HTT CAG repeat size had a large influence on average body weight, the rate of weight loss was largely independent of factors that determine age at onset in $\mathrm{HD}$; and (3) about one-third of the factors that determine the rate of functional, motor, and cognitive progression are different from those that govern age at onset and need further elucidation.

\section{Conclusion}

Our findings imply that targeting of CAG repeat-dependent mechanisms, for example through gene-silencing approaches, is likely to affect the rate of functional, motor, and cognitive impairment, but not weight loss, in manifest HD mutation carriers.

\footnotetext{
From the Department of Neurodegenerative Disease (N.A.A., S.J.T.), UCL Huntington's Disease Centre, University College London Institute of Neurology, UK; Departments of Neurology (N.A.A.) and Public Health and Primary Care (.M.M.v.d.B.), Leiden University Medical Centre, the Netherlands; Department of Population Health Sciences (N.A.A.), German Center for Neurodegenerative Diseases (DZNE), Bonn; and Department of Neurology (G.B.L.), Ulm University Hospital, Germany.

Go to Neurology.org/N for full disclosures. Funding information and disclosures deemed relevant by the authors, if any, are provided at the end of the article. 


\section{Glossary}

$\mathbf{B M I}=$ body mass index; $\mathbf{C I}=$ confidence interval; $\mathbf{H D}=$ Huntington disease; $\mathbf{R A O}=$ residual age at onset; SSRI = selective serotonin reuptake inhibitor; TFC $=$ total functional capacity; TMS $=$ total motor score.

Huntington disease (HD) is an autosomal dominantly inherited neurodegenerative disorder caused by a CAG repeat expansion in the HTT gene resulting in a long polyglutamine tract in the $\mathrm{N}$-terminus of the encoded protein huntingtin. ${ }^{1}$ Involuntary choreiform movements, cognitive impairment, psychiatric and behavioral problems, as well as progressive weight loss characterize the disease. ${ }^{2,3}$ It is well known that the age at onset in HD is inversely associated with the size of the CAG repeat expansion in the mutant allele, accounting for between $47 \%$ and $72 \%$ of the variance in different $\mathrm{HD}$ populations. ${ }^{4}$ Moreover, after controlling for mutation size, of the residual variability in age at onset, about $40 \%$ can be attributed to genes other than the HD gene, while about $60 \%$ can be ascribed to environmental factors. ${ }^{5}$ However, a fundamental but still unresolved issue is whether the factors that determine age at onset in $\mathrm{HD}$ are the same as those that govern disease progression. ${ }^{6-8}$ Elucidation of this issue is of paramount importance because it is, on the one hand, crucial for a better understanding of $\mathrm{HD}$ pathogenesis, and on the other hand, essential for the development as well as optimal timing of administration of novel disease-modifying therapies.

Recently, it was demonstrated that mutant HTT CAG repeat size is strongly associated with both age at onset and age at death in patients with $\mathrm{HD}$, but surprisingly, not with disease duration defined as the difference between the ages at onset and death. ${ }^{9}$ This intriguing finding suggests that either (1) near disease onset, sufficient CAG-dependent damage has accumulated to allow for CAG-independent mechanisms to drive disease progression further and eventually lead to death, or (2) the possibility that mutant huntingtin acts in a CAG-driven manner but with different time courses in various cell types, with affected cell populations responsible for disease onset and death being largely different and independent. ${ }^{9}$ To elucidate this issue further, we hypothesized that if the factors that determine age at onset in $\mathrm{HD}$ would indeed be different from those that dictate disease progression, then this would indicate that the 2 determinants of age at onset, i.e., mutant HTT CAG repeat size and the part of age at onset not determined by CAG repeat size, would be expected to account for only a minor portion of the variability in disease progression. This is because HTT CAG repeat size is by far the strongest determinant of age at onset, while the part of age at onset not determined by CAG repeat size could be regarded as a proxy for all non-CAGdependent determinants of age at onset. ${ }^{5}$ In addition, we hypothesized that if the effects of the determinants of ages at onset and death would be cell-type specific, this would be reflected in different amounts of explained variance in the rate of progression on different clinical domains since their (neuro) pathologic basis is thought to be heterogeneous. ${ }^{10-13}$

\section{Methods}

\section{Patients}

We used monitored data from 5,821 individuals participating in the Enroll-HD study, which also included longitudinal data from 2,488 individuals who had previously participated in the Registry study. ${ }^{14,15}$ Enroll-HD is a global clinical research platform designed to facilitate clinical research in HD. All sites are required to obtain and maintain local ethics committee approvals. Further details are available on the study's website: enroll-hd.org. We retrieved all data from the Enroll-HD website on February 17, 2017, and included in our analysis all participants with a known age at onset (defined as age at clinical HD diagnosis, which strongly correlated with the "rater's estimate of symptom onset" [Pearson $r=0.94, p<$ $0.001]$ ), a mutant CAG repeat size of $\geq 36$, and at least 2 follow-up measurements after disease onset. This resulted in an initial dataset consisting of 3,691 patients with HD. Next, for consistency, we applied the same set of quality-control criteria as proposed before to select a subset of the data for assessment of the association between age at onset and HTT CAG repeat size. ${ }^{9}$ In brief, we first calculated the standard deviation of age at onset for each mutant HTT CAG repeat size, which showed considerable heteroscedasticity for the extremes of CAG repeat size (figure e-1A, links.lww.com/ WNL/A529). Applying a natural log transformation to the age at onset data yielded relative homoscedasticity in the range between 40 and 57 repeats (figure e-1B); therefore, for our analyses, we excluded repeat sizes falling outside this range to ensure that the assumptions for linear regression were not violated. ${ }^{9}$ Subsequently, we plotted the transformed age at onset data against HTT CAG repeat size (figure e-1C) and removed outliers using the standard interquartile range approach according to which outliers are defined as data points outside of 1.5 times the interquartile range below the first or above the third quartile. ${ }^{16}$ This approach resulted in a final dataset consisting of 3,411 individuals, which we used for our main analyses (table e-1, links.lww.com/WNL/A530).

\section{Model development and statistical analysis}

First, we assessed the association between HTT CAG repeat size and the natural logarithm of age at onset as described previously. ${ }^{17}$ As expected, HTT CAG repeat size was strongly associated with age at onset $(\beta=-0.066, p<0.001)$, accounting for $69.3 \%$ of the total variance (figure e-2, links.lww. com/WNL/A529). Checking the regression diagnostics confirmed that the model was not unduly affected by nonnormality, heteroscedasticity, or influential points (figure e-3). Second, using this regression equation, we defined the "residual age at onset" (RAO) as the difference between the actual age at onset and the predicted age at onset based on his 
or her HTT CAG repeat size, after back-transformation of the residuals into the natural scale (figure e-4). Third, for every measurement occasion, we defined disease duration as the difference between the participant's age at that occasion and his/her age at onset. Because disease duration was highly rightskewed (figure e-5A), we used age, which had a near-normal distribution (figure e-5B), as the time variable in our models. Including age as the time indicator also allowed for simultaneous adjustment for possible age effects on disease progression, which would not have been possible with inclusion of disease duration because of a high degree of collinearity between age and disease duration. Based on this information, we then applied a mixed-effects model to the longitudinal data to estimate the interindividual variability in the rate of disease progression in patients with HD by including both fixed and random intercepts and slopes for age as follows:

$$
Y_{i}(t)=\beta_{0}+\beta_{1} \cdot t+b_{0, i}+b_{1, i} \cdot t+\xi_{i}
$$

In this model, $Y_{i}(t)$ represents the clinical score at time $t$ for patient $i, t$ denotes age in years, $\beta_{0}$ represents the mean intercept, $\beta_{1}$ denotes the mean rate of disease progression averaged over the entire cohort, $b_{0, i}$ indicates the random intercept for patient $i$, while $b_{1, i}$ denotes the random slope for patient $i$ (which can be interpreted as the difference between the rate of disease progression for patient $i$ and the average rate of disease progression), and $\xi_{i}$ represents a random residual error term. Therefore, the variation in the rate of disease progression can be defined as the variation in the random slope terms [i.e., $\left.\operatorname{Var}\left(b_{1}\right)\right]$.

For all analyses, model assumptions were verified by inspection of model fits (figure e-6, links.lww.com/WNL/ A529). All tests were 2-tailed, and statistical significance was inferred at $p<0.05$. Programming was performed in $\mathrm{R}$ (version 3.3.2) using the "lme4" package.

\section{Validation through simulation experiments}

Because there are several alternative ways to define the proportion of explained variability (i.e., the coefficient of determination) in linear mixed-effects models, ${ }^{18}$ we used a set of simulation experiments to validate our strategy to quantify variability in the rate of disease progression in $\mathrm{HD}$ for the specific distribution of HTT CAG repeat size, RAO, and age in the Enroll-HD cohort (see table e-2 for a stepwise description, links.lww.com/WNL/A530). As measures of disease progression, we used the rate of change per year in the Unified Huntington's Disease Rating Scale total functional capacity (TFC), total motor score (TMS), and a cognitive summary score. The cognitive summary score was derived by performing a principal components analysis on all Unified Huntington's Disease Rating Scale cognitive subdomains that showed clear progression during follow-up (including the symbol digit modality test, Stroop color naming, word reading and interference tests, as well as verbal fluency tests). This resulted in 5 factors, of which the first (principal component 1) accounted for $79.2 \%$ of the variation, while the other factors each accounted for $8.5 \%$ or less of the variation. Therefore, we used principal component 1 as a cognitive summary score. Our simulation studies demonstrated that, under each scenario, our strategy to determine the variation in the rate of disease progression accurately retrieved the portion of variability that was prespecified as being determined by CAG repeat size, RAO, or both within 5\% precision for TFC, TMS, and the cognitive summary score, and within $11 \%$ precision for body mass index (BMI) (table e-3).

\section{Data availability}

All data used for the analyses in this report are available through Enroll-HD study's website at: enroll-hd.org/forresearchers/access-data.

\section{Results}

\section{Rate of disease progression in relation to mutation size and RAO}

On average, the TFC score decreased by 0.58 points per year (95\% confidence interval [CI]: -0.59 to $-0.56, p<0.001$ ) (table 1). Patients with a higher mutant HTT CAG repeat size had a faster rate of functional decline, while those with a later age at onset than predicted based on their CAG repeat size had a slower rate of functional decline (figure 1, A and B). The average TMS increased with 3.70 points per year (95\% CI: $3.62-3.78, p<0.001$ ), with larger HTT CAG repeat size related to a substantially higher rate of motor progression (figure 1C). Conversely, patients with a higher than expected age at onset had a slower rate of motor deterioration (figure 1D). The cognitive summary score, ranging from -4.79 to 6.65 , declined by 0.26 points per year ( $95 \% \mathrm{CI}:-0.27$ to $-0.25, p<0.001$ ). The effect of expanded HTT CAG repeat size and RAO on cognitive decline followed a remarkably similar pattern to those on functional and motor progression (figure $1, \mathrm{E}$ and $\mathrm{F}$ ). For the assessment of the effects of CAG repeat size and RAO on BMI, we excluded 49 patients with $\mathrm{HD}$ who had extremely low or high body weights (defined as $\mathrm{BMI}<16 \mathrm{~kg} / \mathrm{m}^{2}$ or BMI $>40$ $\mathrm{kg} / \mathrm{m}^{2}$, respectively), because the initial inclusion of these patients resulted in large residuals and thus violation of the statistical model assumptions (data not shown). Average BMI in the resulting group declined by 0.08 units/year (95\% CI: -0.10 to $-0.06, p<0.001)$. There was a substantial influence of HTT CAG repeat size on average body weight, with each one CAG repeat increase associated with 0.55 units lower average BMI (table 1). CAG repeat size was also associated with weight loss, although the effect on the rate of weight decline was considerably less than the effect on average BMI with each one CAG repeat accompanied by 0.01 units/year higher rate of BMI decline (figure $1 \mathrm{G}$ ). Conversely, RAO was not associated with average $\mathrm{BMI}$ and scarcely affected weight loss (figure $1 \mathrm{H}$ ).

\section{Quantification of variation in the rate of disease progression}

First, HTT CAG repeat size alone could account for about half of the variation in the rate of functional, motor, and cognitive 
Table 1 Associations between HTT CAG repeat size, RAO, and clinical progression in HD

\begin{tabular}{|c|c|c|c|c|c|c|c|c|}
\hline & Age $^{a}$ & $C A G^{b}$ & CAG $\times \operatorname{age}^{c}$ & $\mathrm{RAO}^{\mathrm{d}}$ & $\mathrm{RAO} \times$ age $^{\mathrm{e}}$ & $R_{C A G}^{2}{ }^{f}$ & $R_{\mathrm{RAO}}^{2} \mathrm{f}$ & $R_{\mathrm{CAG}+\mathrm{RAO}}^{2}{ }^{\mathrm{f}}$ \\
\hline $\begin{array}{l}\text { Total functional } \\
\text { capacity }\end{array}$ & $\begin{array}{l}-5.78 \times 10^{-1} \\
\left(-5.93 \times 10^{-1} \text { to }\right. \\
\left.-5.64 \times 10^{-1}\right)^{g}\end{array}$ & $-2.03(-2.09 \text { to }-1.97)^{g}$ & $\begin{array}{l}-2.88 \times 10^{-2} \\
\left(-3.18 \times 10^{-2} \text { to }\right. \\
\left.-2.59 \times 10^{-2}\right)^{g}\end{array}$ & $\begin{array}{l}3.87 \times 10^{-1}\left(3.67 \times 10^{-2} \text { to }\right. \\
\left.4.06 \times 10^{-2}\right)^{\mathrm{g}}\end{array}$ & $\begin{array}{l}-5.80 \times 10^{-3}\left(-7.18 \times 10^{-3} \text { to }\right. \\
\left.-4.43 \times 10^{-3}\right)^{\mathrm{g}}\end{array}$ & $45.7(42.5-49.5)$ & $4.8(3.4-5.9)$ & $63.8(60.4-67.6)$ \\
\hline Total motor score & $3.70(3.62-3.78)^{g}$ & $13.74(13.41-13.08)^{g}$ & $\begin{array}{l}2.12 \times 10^{-1} \\
\left(1.95 \times 10^{-1} \text { to }\right. \\
\left.2.29 \times 10^{-1}\right)^{g}\end{array}$ & $-2.23(-2.11 \text { to }-2.34)^{g}$ & $\begin{array}{l}3.36 \times 10^{-2}\left(2.56 \times 10^{-2} \text { to }\right. \\
\left.4.16 \times 10^{-2}\right)^{\mathrm{g}}\end{array}$ & $51.3(48.3-54.3)$ & $5.7(4.6-6.8)$ & $67.2(64.1-70.0)$ \\
\hline $\begin{array}{l}\text { Cognitive summary } \\
\text { score }\end{array}$ & $\begin{array}{l}-2.58 \times 10^{-1} \\
\left(-2.66 \times 10^{-1} \text { to }\right. \\
\left.-2.50 \times 10^{-1}\right)^{g}\end{array}$ & $\begin{array}{l}-9.78 \times 10^{-1} \\
\left(-1.01 \text { to }-9.43 \times 10^{-1}\right)^{g}\end{array}$ & $\begin{array}{l}-1.66 \times 10^{-2} \\
\left(-1.84 \times 10^{-2} \text { to }\right. \\
\left.-1.49 \times 10^{-2}\right)^{g}\end{array}$ & $\begin{array}{l}1.13 \times 10^{-1}\left(1.01 \times 10^{-1}\right. \\
\text { to } 1.25 \times \\
\left.10^{-1}\right)^{\mathrm{g}}\end{array}$ & $\begin{array}{l}-1.36 \times 10^{-3}\left(-2.22 \times 10^{-3} \text { to }\right. \\
-5.11 \times \\
\left.10^{-4}\right)^{\mathrm{g}}\end{array}$ & $48.2(44.3-52.1)$ & $1.7(0.9-2.8)$ & $53.7(49.7-57.6)$ \\
\hline BMI & $\begin{array}{l}-8.12 \times 10^{-2} \\
\left(-1.01 \times 10^{-1} \text { to }\right. \\
\left.-6.12 \times 10^{-2}\right)^{g}\end{array}$ & $\begin{array}{l}-5.47 \times 10^{-1} \\
\left(-6.27 \times 10^{-1} \text { to }\right. \\
\left.-4.66 \times 10^{-1}\right)^{g}\end{array}$ & $\begin{array}{l}-1.19 \times 10^{-2} \\
\left(-1.63 \times 10^{-2} \text { to }\right. \\
\left.-7.52 \times 10^{-3}\right)^{g}\end{array}$ & $\begin{array}{l}1.72 \times 10^{-2}\left(-1.16 \times 10^{-2} \text { to }\right. \\
\left.4.60 \times 10^{-2}\right)\end{array}$ & $\begin{array}{l}-3.10 \times 10^{-3}\left(-5.13 \times 10^{-3} \text { to }\right. \\
-1.07 \times \\
\left.10^{-3}\right)^{\mathrm{h}}\end{array}$ & $3.3(1.7-4.9)$ & $0.0(-0.2$ to 0.4$)$ & $3.7(2.0-5.5)$ \\
\hline
\end{tabular}

Abbreviations: $\mathrm{BMI}=$ body mass index; $\mathrm{HD}=$ Huntington disease; $\mathrm{RAO}=$ residual age at onset.

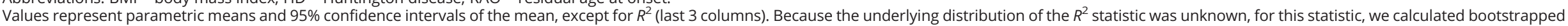

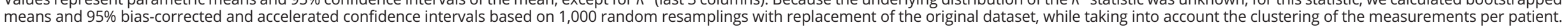
means and $95 \%$ bias-corrected and accelerated confidence intervals based on 1,000 random resamplings with replacement of the original dataset, while taking into account the
a This column contains the regression coefficients associated with age, which can be interpreted as the rate of disease progression per year in units of the outcome measure.

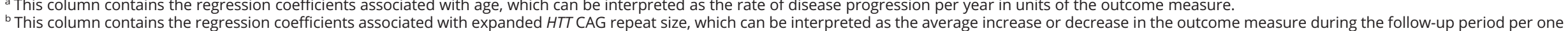

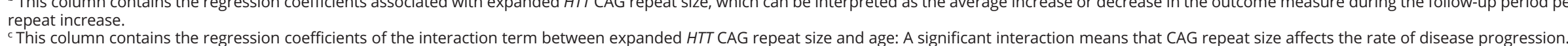

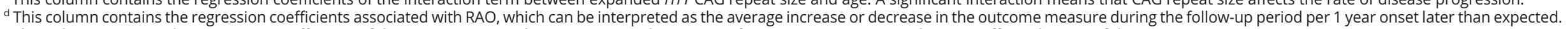

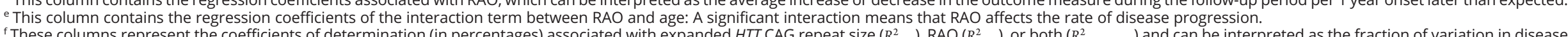

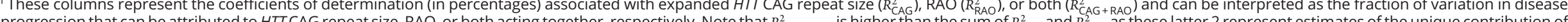
progression that can be atributed to

${ }_{\mathrm{h}} p<0.001$
$\mathrm{~h}$ 
Figure 1 Association between the rate of clinical progression and HTT CAG repeat size and residual age at onset
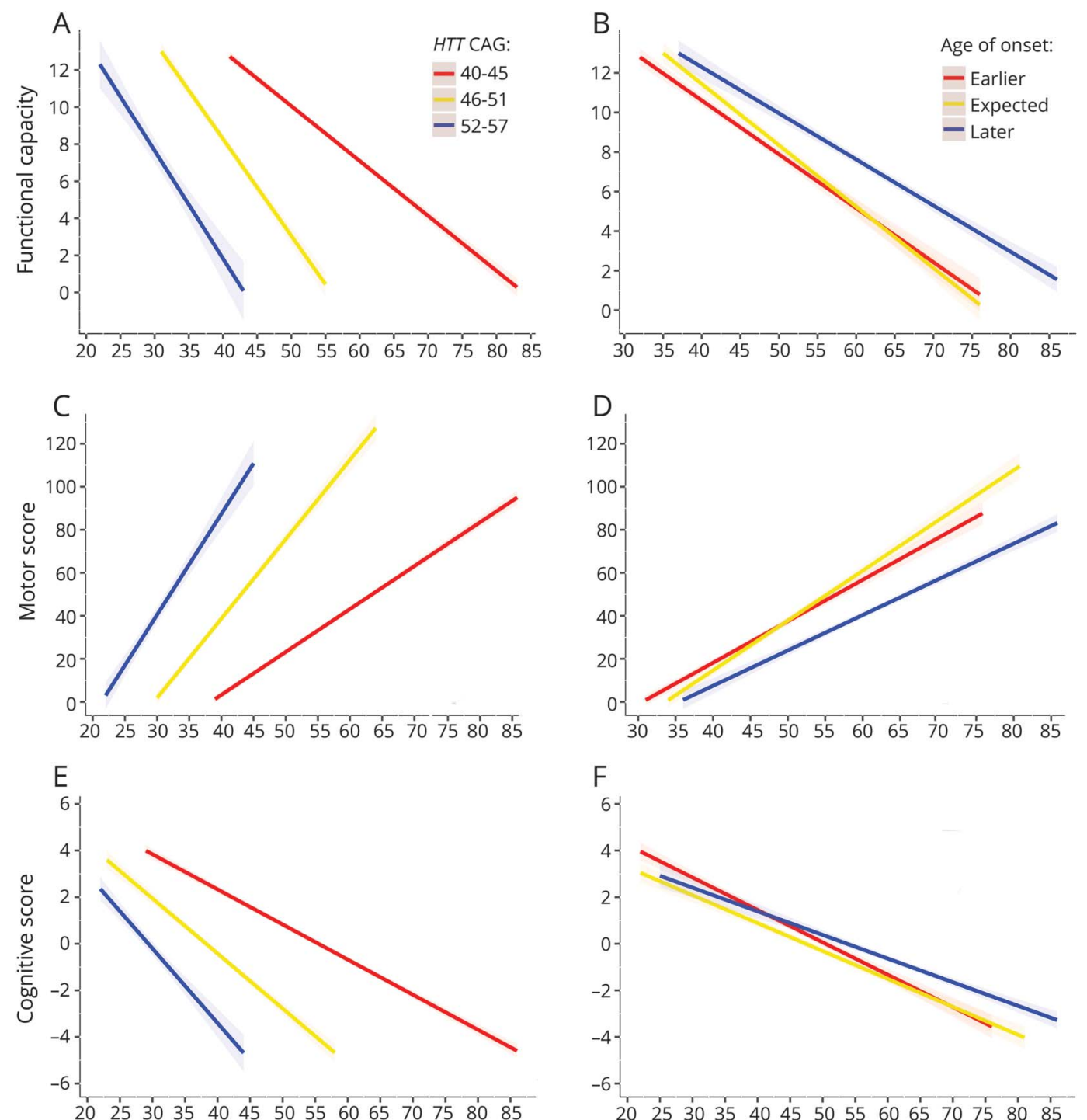

$\mathrm{F}$
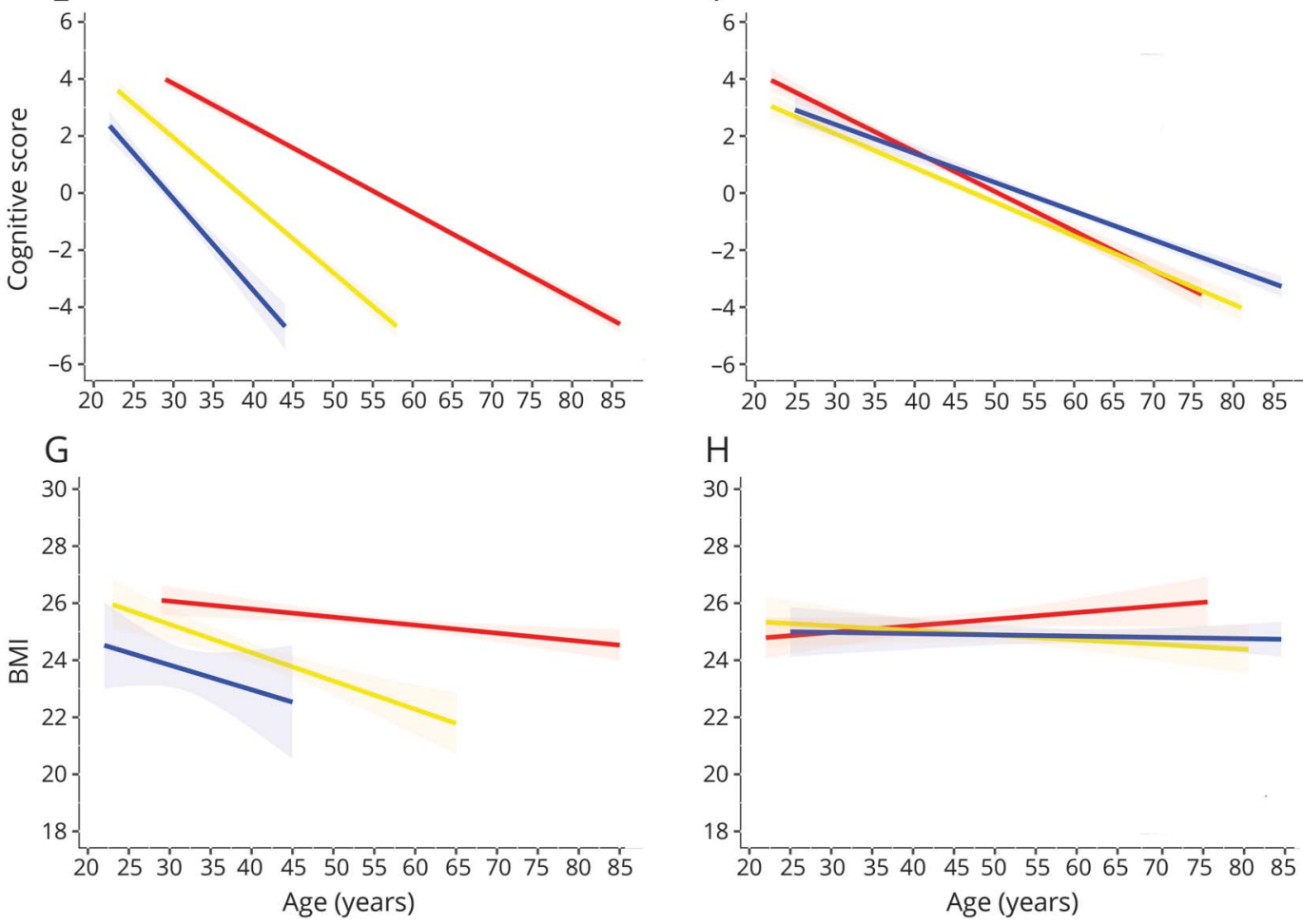

$\mathrm{H}$

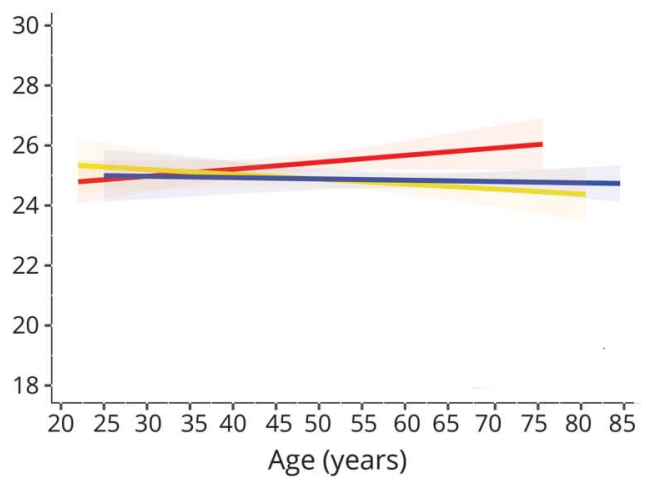

To further explore and visualize the data, we first divided the patient cohort in 3 different groups based on either CAG repeat size (A, C, E, and G) or residual age at onset (B, D, F, and H). Next, for each clinical measure and each category of CAG repeat size or residual age at onset, we applied a separate linear mixedeffects model to estimate the mean trajectory of change in clinical scores in time for different categories of HTT CAG repeat size or residual age at onset. The rate of deterioration on the Unified Huntington's Disease Rating Scale total functional capacity $(A)$ total motor score $(C)$, a cognitive summary score $(E)$, and body mass index (BMI) (G) increased significantly with a larger expanded HTT CAG repeat size. Conversely, the rate of functional (B), motor (D), and cognitive decline (F) was slower in those patients who had an age at onset later than that expected based on their expanded HTT CAG repeat size compared to those with an age at onset at or earlier than expected based on their expanded HTT CAG repeat size. However, residual age at onset had no influence on the rate of weight loss $(H)$. The straight lines represent the mean predicted scores while the dashed areas around the regression lines denote the $95 \%$ confidence intervals of the mean. The 3 categories of expected age at onset, i.e., "earlier," "expected," and "later," were defined based on tertiles of residual age at onset as minimum (-16.4) to $\leq-2.3,>-2.3$ to $\leq 2.9$, and $>2.9$ to maximum $(21.8)$ years, respectively. 


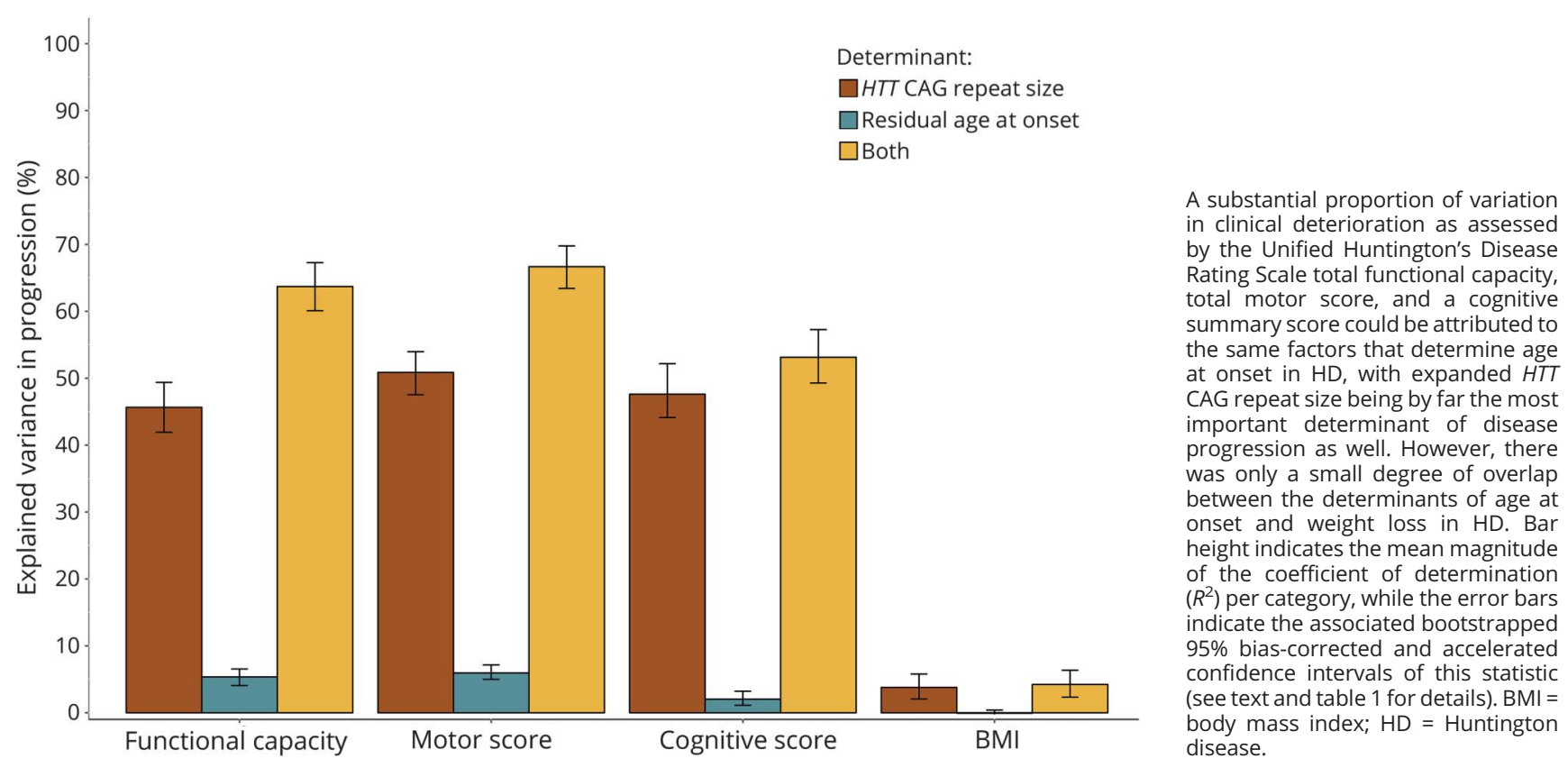

deterioration in patients with $\mathrm{HD}$ (table 1, figure 2). Second, the unique effect of RAO, independent of HTT CAG repeat size, on variation in the rate of functional, motor, and cognitive impairment was very modest, ranging between $2 \%$ and $6 \%$. However, in conjunction with HTT CAG repeat size, RAO could account for a considerably higher amount of variation in disease progression, ranging from $5 \%$ to about $20 \%$, on these clinical domains (table 1), suggesting the factors that are represented by RAO influence the rate of progression in HD largely through their interaction with HTT CAG repeat-dependent mechanisms. Third, although HTT CAG repeat size was associated with the rate of weight loss, it explained only about $3 \%$ of its variation, while RAO did not account for any variation in the rate of weight loss (figure 2). Given that certain widely used medications, including neuroleptics (especially olanzapine), tetrabenazine, and antidepressants (particularly selective serotonin reuptake inhibitors [SSRIs]), could affect motor symptoms and/or body weight, ${ }^{15,19}$ we also repeated the analyses while adjusting for the use of these medications. This was achieved by encoding past or current use of olanzapine, neuroleptics other than olanzapine, tetrabenazine, SSRIs, and antidepressants other than SSRIs into 5 binary variables and including them as well as their interactions with age in the models. However, our findings did not change materially after adjustment for use of these medications (data not shown).

\section{Sensitivity analysis}

In theory, exclusion of outliers could lead to selection bias. To assess this possibility, we repeated all the analyses on the complete dataset, i.e., with inclusion of all participants who had 2 or more measurements available $(n=3,691)$. The analyses of the complete dataset did not materially change any of the results (table e-4, links.lww.com/WNL/A530).

\section{Discussion}

The extent of overlap between the determinants of age at onset and disease progression in HD has received little study. Given the conceptual challenges posed by the absence of a well-validated method to estimate the coefficient of determination in longitudinal models, here we first validated the accuracy of an intuitive approach to quantify the degree of explained variability in the rate of progression in HD using simulation experiments. Application of this approach to data collected as part of Enroll-HD, the largest cohort of patients with HD currently available, yielded several fundamental insights into HD pathogenesis.

First, our findings demonstrate that about two-thirds of the variation in the rate of functional, motor, and cognitive impairment is dictated by the same factors that also determine age at onset in HD, with expanded HTT CAG repeat size being by far the most important determinant of the rate of clinical deterioration. This finding thus narrows the range of alternatives implied by the lack of an association between HTT CAG repeat size and disease duration ${ }^{9}$ : Our findings indicate that CAGdependent mechanisms continue to drive pathogenesis even after disease onset. In fact, we showed that even the factors that determine RAO in HD assert their main influence on disease progression through their interplay with HTT CAG repeat size. A major clinical corollary of this result is that targeting of CAGdependent mechanisms, for example through gene-silencing approaches, ${ }^{20}$ is also likely to affect functional, motor, and 
cognitive progression in those who already have manifest disease. Moreover, in consideration of future clinical trials in $\mathrm{HD}$, our findings indicate that it is imperative to adjust the outcome for differences in both mutant HTT CAG repeat size and RAO between the control and treatment arms, as these are major determinants of the rate of disease progression and, consequently, controlling for them could substantially increase statistical power to detect treatment-induced effects.

Second, our study also supports the notion that the (neuro) pathologic basis of age at onset and age at death are likely to be different in HD because this is conceivably the only possibility that could reconcile our findings with those of Keum et al. ${ }^{9}$ who found that HTT CAG repeat size is a major determinant of age at onset and age at death, but not of disease duration. Indeed, given that HTT CAG repeat size is the major determinant of age at onset, disease progression, and age at death, the only possibility that would allow for a disease duration independent of CAG repeat size ${ }^{9}$ would be a different neuroanatomical basis for, on the one hand, age at onset and disease progression (at least on functional, motor, and cognitive domains) and, on the other hand, age at death. The fact that we found that the determinants of age at onset also largely dictate the rate of motor and cognitive progression, but not the rate of weight loss, is particularly interesting in this regard: Pathology of the basal ganglia and cerebral cortex, which largely underlie motor and cognitive impairment, is unlikely to determine age at death because if that would have been the case, disease duration, defined as the interval between the ages at onset and death, would have been shorter for patients with a larger HTT CAG repeat size given their substantially faster rate of progression in these domains. ${ }^{9}$ However, our results demonstrate that weight loss, a cardinal feature of $\mathrm{HD}$, is largely independent of the factors that determine age at onset and, therefore, its root causes might reflect pathology of other central or peripheral structures that might underlie eventual death. Indeed, weight loss in HD might reflect pathology of hypothalamic and (autonomic) brain stem structures that are crucial for systemic homeostasis, including swallowing, respiration, and cardiovascular control, paralleling findings in other polyglutamine disorders. $^{21-23}$ In this regard, it is especially interesting to note that the most frequent causes of death in patients with $\mathrm{HD}$ are (aspiration) pneumonia and heart disease. ${ }^{24,25}$ Given that the effect of expanded HTT CAG repeat size on average $\mathrm{BMI}$ is much larger than on the rate of weight loss, ${ }^{13}$ the effect of CAG repeat-dependent mechanisms on body weight either commences many years before age at onset, which in practical terms mainly reflects age at motor onset, or is present from birth. Indeed, children carrying the HTT CAG repeat expansion have been found to have a lower BMI compared to mutation-negative controls. ${ }^{26,27}$ In any case, given the robust association between body weight and disease progression in $\mathrm{HD},{ }^{13}$ it is of paramount importance to elucidate the responsible mechanisms and assess whether energy-based therapeutics, such as dietary interventions, would affect disease progression.
And finally, our findings imply that about one-third of the factors that affect the rate of functional, motor, and cognitive progression in $\mathrm{HD}$ are likely to be different from those that determine age at onset. It is still unknown which specific mechanisms might be involved in this respect, but it is likely that the underlying pathogenic pathways will include those that show increased activity with disease progression such as neuroinflammation. ${ }^{28,29}$

A limitation of our study is lack of imaging or biochemical measures of disease progression. Therefore, we were unable to identify the structures or mechanisms whose progressive pathology is most robustly influenced by the determinants of age at onset.

We demonstrated that about two-thirds of the rate of functional, motor, and cognitive progression in HD is determined by the same factors that also determine age at onset, with CAG repeat-dependent mechanisms having by far the largest effect. Conversely, the rate of weight loss is likely to be largely influenced by other factors that need further elucidation. Thus, targeting of CAG repeatdependent mechanisms, for example through gene-silencing approaches, has the potential to affect the rate of functional, motor, and cognitive impairment in manifest HD, but not the rate of weight loss.

\section{Author contributions}

Ahmad Aziz: study concept and design, acquisition of data, analysis and interpretation of data. Jorien van der Burg: study concept and design, acquisition of data, interpretation of data. Sarah Tabrizi: interpretation of data, critical revision of manuscript for intellectual content. Bernhard Landwehrmeyer: acquisition of data, interpretation of data, critical revision of manuscript for intellectual content.

\section{Acknowledgment}

Enroll-HD is a longitudinal observational study for Huntington disease families intended to accelerate progress toward therapeutics; it is sponsored by the CHDI Foundation, a nonprofit biomedical research organization exclusively dedicated to developing therapeutics for HD. Enroll-HD would not be possible without the vital contribution of the research participants and their families. The authors thank Professor Raymund A.C. Roos for his comments on an earlier version of the manuscript.

\section{Study funding}

N.A.A. was supported by a VENI grant (91615080) from the Netherlands Organisation of Scientific Research and a Marie Skłodowska-Curie Individual Fellowship grant from the European Union (Horizon 2020, 701130).

\section{Disclosure}

The authors report no disclosures relevant to the manuscript. Go to Neurology.org/N for full disclosures. 
Received October 16, 2017. Accepted in final form March 14, 2018.

\section{References}

1. The Huntington Disease Collaborative Research Group. A novel gene containing a trinucleotide repeat that is expanded and unstable on Huntington's disease chromosomes. Cell 1993;72:971-983.

2. Roos RA. Huntington's disease: a clinical review. Orphanet J Rare Dis 2010;5:40.

3. Walker FO. Huntington's disease. Lancet 2007;369:218-228.

4. Cazeneuve C, Durr A. Genetic and molecular studies. In: Bates GP, Tabrizi SJ, Jones L, editors. Huntington's Disease, 4th ed. New York: Oxford University Press; 2014: 109-130.

5. Wexler NS, Lorimer J, Porter J, et al. Venezuelan kindreds reveal that genetic and environmental factors modulate Huntington's disease age of onset. Proc Natl Acad Sci USA 2004;101:3498-3503.

6. Moss DJH, Pardinas AF, Langbehn D, et al. Identification of genetic variants associated with Huntington's disease progression: a genome-wide association study. Lancet Neurol 2017;16:701-711.

7. Rosenblatt A, Kumar BV, Mo A, Welsh CS, Margolis RL, Ross CA. Age, CAG repeat length, and clinical progression in Huntington's disease. Mov Disord 2012;27: 272-276.

8. Ravina B, Romer M, Constantinescu R, et al. The relationship between CAG repeat length and clinical progression in Huntington's disease. Mov Disord 2008;23: 1223-1227.

9. Keum JW, Shin A, Gillis T, et al. The HTT CAG-expansion mutation determines age at death but not disease duration in Huntington disease. Am J Hum Genet 2016;98: 287-298.

10. Kim EH, Thu DC, Tippett LJ, et al. Cortical interneuron loss and symptom heterogeneity in Huntington disease. Ann Neurol 2014;75:717-727.

11. Singh-Bains MK, Tippett LJ, Hogg VM, et al. Globus pallidus degeneration and clinicopathological features of Huntington disease. Ann Neurol 2016;80:185-201.

12. Waldvogel HJ, Kim EH, Tippett LJ, Vonsattel JP, Faull RL. The neuropathology of Huntington's disease. Curr Top Behav Neurosci 2015;22:33-80.

13. van der Burg JMM, Gardiner SL, Ludolph AC, Landwehrmeyer GB, Roos RAC, Aziz NA. Body weight is a robust predictor of clinical progression in Huntington disease. Ann Neurol 2017;82:479-483.
14. Orth M, Handley OJ, Schwenke C, et al. Observing Huntington's disease: the European Huntington's disease Network's REGISTRY. J Neurol Neurosurg Psychiatry 2011;82:1409-1412.

15. Landwehrmeyer GB, Fitzer-Attas CJ, Giuliano JD, et al. Data analytics from enroll$\mathrm{HD}$, a global clinical research platform for Huntington's disease. Mov Disord Clin Pract 2017;4:212-224.

16. Lee JM, Ramos EM, Lee JH, et al. CAG repeat expansion in Huntington disease determines age at onset in a fully dominant fashion. Neurology 2012;78:690-695.

17. Langbehn DR, Hayden MR, Paulsen JS. CAG-repeat length and the age of onset in Huntington disease (HD): a review and validation study of statistical approaches. Am J Med Genet B Neuropsychiatr Genet 2010;153B:397-408.

18. Nakagawa S, Schielzeth H. A general and simple method for obtaining R2 from generalized linear mixed-effects models. Methods Ecol Evol 2013;4:133-142.

19. Aziz NA, van der Marck MA, Pijl H, Olde Rikkert MG, Bloem BR, Roos RA. Weight loss in neurodegenerative disorders. J Neurol 2008;255:1872-1880.

20. Wild EJ, Tabrizi SJ. Therapies targeting DNA and RNA in Huntington's disease. Lancet Neurol 2017;16:837-847.

21. Zoghbi HY, Orr HT. Pathogenic mechanisms of a polyglutamine-mediated neurodegenerative disease, spinocerebellar ataxia type 1. J Biol Chem 2009;284:7425-7429.

22. van Wamelen DJ, Aziz NA, Roos RA, Swaab DF. Hypothalamic alterations in Huntington's disease patients: comparison with genetic rodent models. J Neuroendocrinol 2014;26:761-775.

23. Hult S, Soylu R, Bjorklund T, et al. Mutant huntingtin causes metabolic imbalance by disruption of hypothalamic neurocircuits. Cell Metab 2011;13:428-439.

24. Heemskerk AW, Roos RA. Aspiration pneumonia and death in Huntington's disease. PLoS Curr 2012;4:RRN1293.

25. Abildtrup M, Shattock M. Cardiac dysautonomia in Huntington's disease. J Huntingtons Dis 2013;2:251-261.

26. Marder K, Mehler MF. Development and neurodegeneration: turning HD pathogenesis on its head. Neurology 2012;79:621-622.

27. Lee JK, Mathews K, Schlaggar B, et al. Measures of growth in children at risk for Huntington disease. Neurology 2012;79:668-674.

28. Andre R, Carty L, Tabrizi SJ. Disruption of immune cell function by mutant hun tingtin in Huntington's disease pathogenesis. Curr Opin Pharmacol 2016;26:33-38.

29. Politis M, Lahiri N, Niccolini F, et al. Increased central microglial activation associated with peripheral cytokine levels in premanifest Huntington's disease gene carriers. Neurobiol Dis 2015;83:115-121. 


\section{Neurology}

\section{Overlap between age-at-onset and disease-progression determinants in Huntington disease}

N. Ahmad Aziz, Jorien M.M. van der Burg, Sarah J. Tabrizi, et al. Neurology 2018;90;e2099-e2106 Published Online before print May 9, 2018

DOI 10.1212/WNL.0000000000005690

\section{This information is current as of May 9, 2018}

\section{Updated Information \& Services}

References

Citations

Subspecialty Collections

Permissions \& Licensing

Reprints including high resolution figures, can be found at: http://n.neurology.org/content/90/24/e2099.full

This article cites 28 articles, 6 of which you can access for free at: http://n.neurology.org/content/90/24/e2099.full\#ref-list-1

This article has been cited by 2 HighWire-hosted articles: http://n.neurology.org/content/90/24/e2099.full\#\#otherarticles

This article, along with others on similar topics, appears in the following collection(s):

\section{Cohort studies}

http://n.neurology.org/cgi/collection/cohort_studies

Huntington's disease

http://n.neurology.org/cgi/collection/huntingtons_disease

Natural history studies (prognosis)

http://n.neurology.org/cgi/collection/natural_history_studies_prognosis

Information about reproducing this article in parts (figures,tables) or in its entirety can be found online at:

http://www.neurology.org/about/about_the_journal\#permissions

Information about ordering reprints can be found online:

http://n.neurology.org/subscribers/advertise

Neurology ${ }^{\circledR}$ is the official journal of the American Academy of Neurology. Published continuously since 1951, it is now a weekly with 48 issues per year. Copyright @ 2018 The Author(s). Published by Wolters Kluwer Health, Inc. on behalf of the American Academy of Neurology.. All rights reserved. Print ISSN: 0028-3878. Online ISSN: 1526-632X.

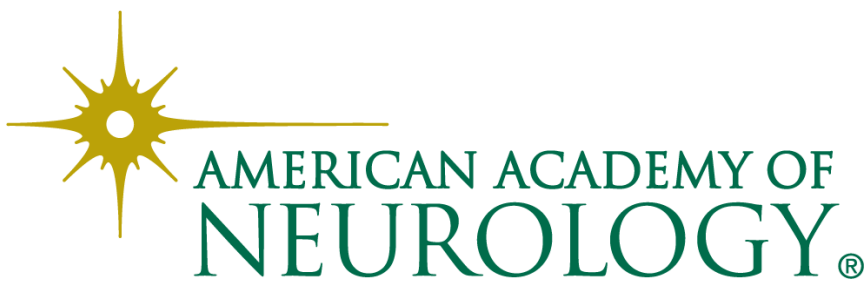

